1. Es zeigt fich, baß̉ bie gläbe bes forftlich genubten Bobens in

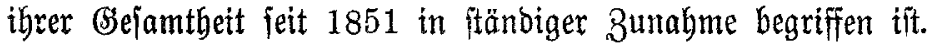

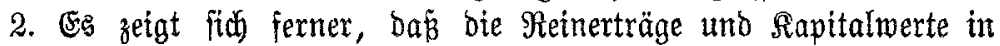

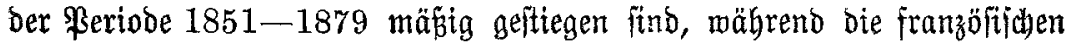

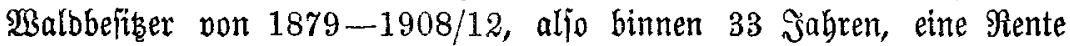
von 44 Mitl. und ein Sapital von 1267 Mid. Frf. verloren haben. Shre gegermärtige Rage gleidht berjenigen, wie fie faton 1851 feitgeftellt wurbe: in jener Beit erhob fid ber gejamte Reinertrag ichon auf 153 Mill. uno ber gefamte Rapitalwert auf 4824 Mitll. Frtl., wäbrent 1908/12 erft 141 Mitl. und aud nur 4823 Mill. Frt. ermittelt murben. 2Aljo tros

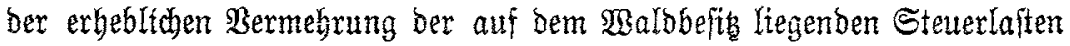
und der in bie Millionen gehenden 2 ufforftungstoften uiw. bez̧ieht ber Walsbefitber in Franfreich beute eine etwas geringere Rente als vor

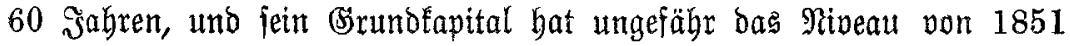
behauptet.

3. Und es zeigt fich endlich, bấ bie Reinerträge etwas ftärter ge= fallen find, als die Sapitalmerte. Die mittlern Syettarreinerträge haben feit $187926,08 \%$, bie entipredenden $\mathfrak{S}$ eftarfaufmerte $23,08 \%$ einge=

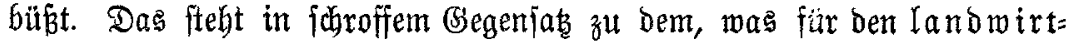


ftart gejunten find wie bie Sapitalmerte, aljo weniger bie lanbwirtichaft=

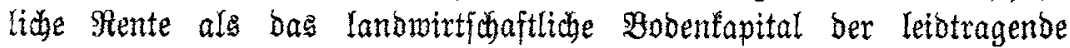
Ieil ift.

\title{
Künftliche Gerbftoffe.
}

Bon Dberforitrat a. D. Éslinger.

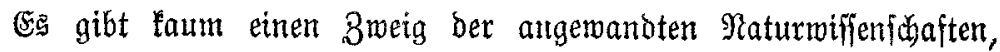
ber ung in ber neueren uno neueften Beit fo midhtige, wirtichaftlich tief

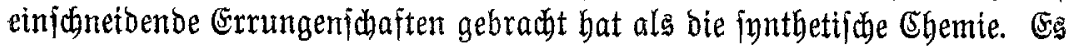
barf ja nur an bie Daritellung des fünftltcten J̌nbigo erinnert merben, bann an bie für bie Siriegegzeit io bebeutfam getworbente Nub̧barmadjung bes Ruftificfitoffes zur Bereitung bes in ber Ranbwirtidaft fo widtigen Sticfitoffoüngers forwie zu militärifichen 3meden, ferner an bie fürzlich ge= lungene fünflticte $\mathfrak{g}$ erftellung bes bejonbers fïr bie $\mathfrak{A r m e e}$ jo wertoollen Sautjuluts. 2lls eine fehr meittragenbe, im allgemeinen noch weniger befannte Entbectung ift nun bie Daritellung fünftitber Berbitoffe zu ver=

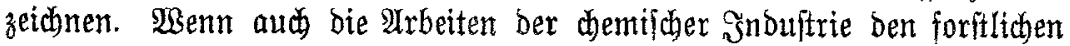
Sireijen im allgemeinen etwas ferne liegen, fo bürfte boc bie Möglich= 
feit, Gerbitoffe auf fünfittchem $\mathfrak{B e g e ~ z u t ~ e r z e u g e n , ~ a u s ~ n a h e l i e g e n d e n ~ G r u ̈ n = ~}$ ben Şntereffe genug bieten, um eine kuzze Mitteilung in diejem Blatte zu reditfertigen.

Mad) eingehenden Sorarbeiten ift es zuerit Frofefior Stiasny

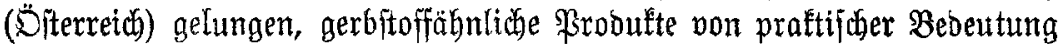
auf innthetijochem $\mathfrak{B}$ ege barzuftellen.

Das burch Fatente im Şn= und 2utsland gejchühte Berfahren wird

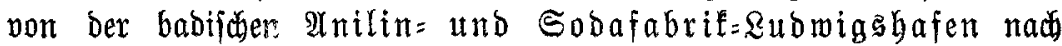
weiterer Bervolffommnung bereits im groß̈en angemendet. 8 wei $\mathfrak{B e r}=$ treter ber finthetifden Gerbitoffe find unter ber Bezeidinung Merabol D und Rerabol ND fchon in ben Berfebr eingefübrt. Es bürfte fich er= übrigen, in biejem Blatte auf bie felbitberftänblich nur in allgemetnen

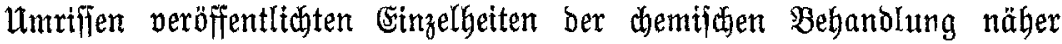
einz̧ugehen uno fei nur erwähnt, baj zur Darftellung von Reraool $D$ bie im Steinfohlenteer enthaltenen \$henole uno Frejole mit Frormaldehyo und Schmefeljäure in entiprechende Sheattion verjekt merben, wobei ein in Maffer löeliches \$robuft ftch bildet, das ein ben natürliden Gerb= itoffen ähnliches Serbalten zeigt.

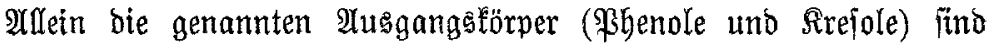
nach) einer feitens ber genannten Fabrif mir gemorbenen Mitteilung zu Seereşzocten bejhlagnahmt und muf beshalb auf bie Bewinnung von Rerabol $D$ vorerit verzichtet werben. (Ss ift jeood gelungen, in ber IInilin= unb Sobafabril Rubwigghafen auf anderer (Strundlage, ๖. h. ohne

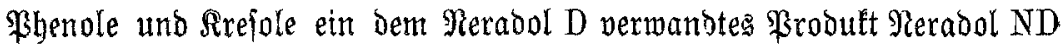
zut gewinnen. Diejes ift mehr dünffüfifig, bildet mit $\mathfrak{B a f f e r}$ in jedem

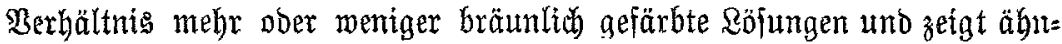
lid wie bie natürlichen pflanzlichen Gerbitoffe faure Reaftion.

Mit ben genannten betben \$roduften find in Eaboratorien, in Reder= fabrifelt bejonders auth bei ber Berfuctsanfalt für Reberinbuitrie in

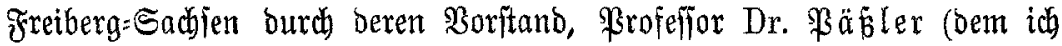
bieje Mitteilungen verbanfe), eingehende Berjuche gemact worden, bie übereinfitimmend zat bem Ergebnis geführt baben, baßj beibe Präparate

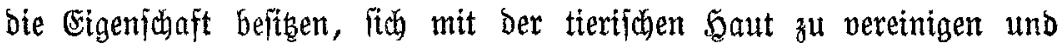
biefe in Reber zu vermanbeln. Ses ift gelungen, leichtere Reberjorten aus Edaj= und Biegenfellen, aber aud Ralbleber uno jogar fabmeres Soghls

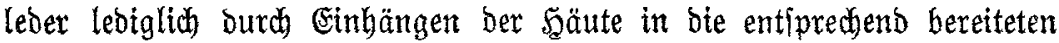

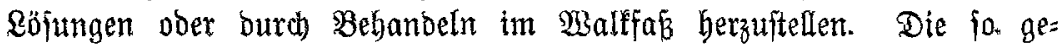
wonnenen Seder zeigen alle eine belle, fait meipe Farbe und find auf=

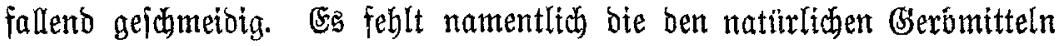

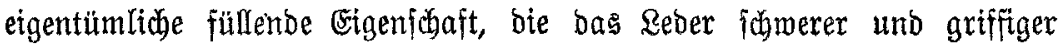


madt. Dabei befteben feinere Unterfditede in ber WBirfung von Nerabol $D$ und $N D$, auf bie jebod bier nidht näher eingegangen werben will.

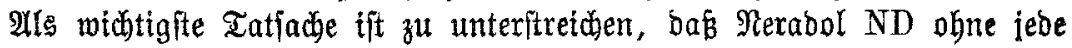

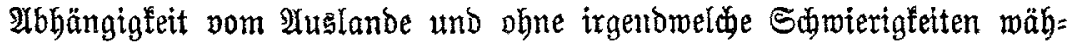
renb bes Rrieges aus jeberzeit verfügbaren Materialien bergeftellt werben fann. Die Berjuche baben bis jekt ergeben, dab fich bie fünitlichen Berb= ftoffe in reiner Frorm nur für leidtere Reberjorten, aud geipaltene Suaf: felle gut etgnen, bas bagegen bei ber Saerftellung von fibwererem Reber pflanzliche Gerbitoffe mit verwendet werben jollen. (s) find in biefer Şinficht fobn verfobiedene Berfuche unter Mitbemusung von Ertraften

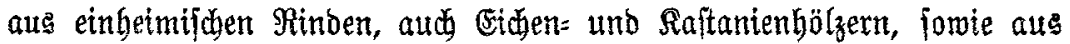
auslänbifchen Berbmitteln gemadbt worden, die ein befriebigendee Er: gebris gezeigt haben. Bei ber Neubeit Der Sache find jelbitverftändich

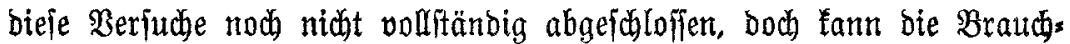
barfeit ber fömitliden Berbitoffe als gefictert betrachtet werden.

Bom Stanopuntt der 2llgemeinheit ift biejer neute grobe Erfolg ber fynthetijoen Ebemie vorbehaltlos zu begrïßen, da er uns bejonders jezt wäbrend bes Arieges bie Bereitung bes in jo groper Menge für die Armee und aud jo oft gebraudften \&ebers fiber ftellt. Mber aud fpäter nad) Whtederfehr bes Friedens vermögen bie fünttliden (serbftoffe wejent= lich bazu beizutragen, uns vom $\mathfrak{A} u s \mathfrak{s}$ and unabjängig zu machen uno boffentlid auch bas Reber zu verbilligen.

Die forftliden Jntereffenten fteben ber Sadje allerbings mit etwas gemifbten Gsefühlen gegenüber. Dem wenn bie Bitufung eintreten jollte,

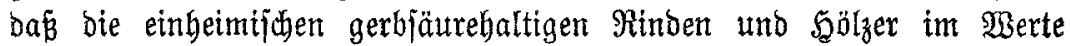

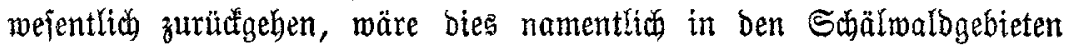
wegen ber vielen beteiligten Gemeinden und $\$$ srivaten zu bebauern.

2Ulein, wie fibn bemertt, es find bie inländichen Pflanzengerbftoffe vorerit nicht zut entbebren, aubb foll nad) jadberitänoiger Mitteilung bie Technif vorläuftg noch nidjt in ber Rage jein, bie fünftlichen Gerbmittel

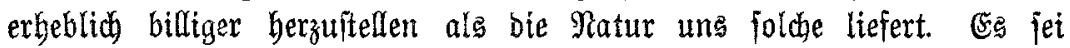

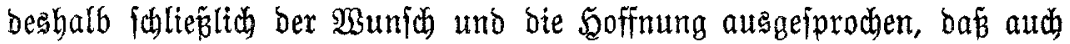
nach dem Irieg ber Schälwaldbetrieb unb bie Bewinnung von Fidgtenrinde énigermą̧en befriedigenbe Errträge abmerfen möcten! 